\title{
Left Ventricular Assist Device and the Kidney: Getting to the Heart of the Matter
}

\author{
Mayanka Kamboj Amir Kazory \\ Division of Nephrology, Hypertension, and Renal Transplantation, University of Florida, Gainesville, FL, USA
}

\author{
Keywords \\ Left ventricular assist device · Heart failure · Kidney \\ dysfunction - Cardiorenal syndrome
}

\begin{abstract}
Left ventricular assist devices (LVADs) are increasingly used for the management of patients with advanced heart failure (AHF) due to their established salutary impact on hemodynamic status and survival benefit. Impairment in kidney function is common in the setting of AHF and is associated with adverse impact on the outcomes. Cardiorenal interactions represent a complex pattern in these patients rendering their care a challenge that needs to be addressed by multidisciplinary approaches. Following LVAD implantation, AHF patients have the potential to achieve marked improvement in kidney function due to increased cardiac output and kidney perfusion as well as reduction in renal venous congestion. However, a subset of these patients is also at risk for acute kidney injury and resurgence of kidney dysfunction on continued mechanical circulatory support. Herein, we provide an overview of various aspects of changes in kidney function pre- and post-LVAD implantation, review potential underlying pathophysiologic mechanisms, and the impact on the outcomes. Moreover, the currently available data on renal replacement therapy of LVAD-treated patients, whether in the acute setting or as a maintenance therapy, are discussed in detail along with areas of high clinical relevance where a clear gap in knowledge exists.
\end{abstract}

๑ 2019 S. Karger AG, Basel

E-Mail karger@karger.com www.karger.com/bpu

\section{Introduction}

Heart failure (HF) is a public health problem affecting nearly 6.5 million people in the United States with a reported incidence of 21 per 1,000 in population above the age of 65 years [1]. A trend toward increased incidence and prevalence of HF has been noted in the last decade, which is likely attributed to improved survival after a cardiac ischemic event, implementation of strategies for risk factor modification, more advanced cardiac revascularization techniques, implantation of cardiac defibrillators, and aging population [2]. Although the survival has been improving, its reported mortality continues to be high; 1-year mortality has been reported to be approximately $30 \%$ among Medicare beneficiaries [3]. Approximately 1 million people are admitted to the hospital annually for treatment of HF and it represents the most common cause of hospitalization in patients over 65 years of age [4]. As such, with ever-growing prevalence, the epidemic of HF has become a huge economic burden on the health care system. In year 2012, the direct medical cost for HF was estimated to be 20.9 billion dollars and is projected to increase by 2.5 -fold in 2030 [5].

\section{Advanced Therapy for HF}

Several advanced treatment strategies have emerged in the last few decades, which have revolutionized therapy of patients with refractory HF. American College of Cardiol- 
Table 1. Heart failure classification

\begin{tabular}{lc}
\hline ACCF/AHA HF classification - objective assessment [6] & NYHA functional classification - subjective assessment [7] \\
$\begin{array}{l}\text { A. At high risk for HF but without structural heart } \\
\text { disease or symptoms of HF }\end{array}$ & $\begin{array}{l}\text { I. No limitation of physical activity. Ordinary physical activity does } \\
\text { not cause undue fatigue, palpitation, dyspnea (shortness of breath) }\end{array}$ \\
\hline $\begin{array}{l}\text { B. Structural heart disease but without signs or } \\
\text { symptoms of HF }\end{array}$ & $\begin{array}{c}\text { II. Slight limitation of physical activity. Comfortable at rest. } \\
\text { Ordinary physical activity results in fatigue, palpitation, dyspnea } \\
\text { (shortness of breath) }\end{array}$ \\
$\begin{array}{l}\text { C. Structural heart disease with prior or current } \\
\text { symptoms of HF }\end{array}$ & $\begin{array}{l}\text { III. Marked limitation of physical activity. Comfortable at rest. } \\
\text { Less than ordinary activity causes fatigue, palpitation, or dyspnea }\end{array}$ \\
$\begin{array}{l}\text { D. Refractory HF requiring specialized interventions } \\
\text { IV. Unable to carry on any physical activity without discomfort. } \\
\text { Symptoms of heart failure at rest. If any physical activity is } \\
\text { undertaken, discomfort increases }\end{array}$
\end{tabular}

ACCF, American College of Cardiology Foundation; AHA, American Heart Association; NYHA, New York Heart Association; HF, heart failure.

ogy Foundation and American Heart Association classify HF patients into 4 categories based on objective assessment of disease severity and symptoms with the laudable goal of achieving minimal or no symptoms (i.e., Class A, $\mathrm{B}$, Table 1 ) with treatment in a majority of the patients $[6$, 7]. However, in patients who have marked limitation in performing less than ordinary activity or any activity with moderate to severe cardiovascular disease (i.e., Class C, D $\mathrm{HF}$ ), short-term treatment options include intra-aortic balloon pump, percutaneous micro axial left ventricular assist device (LVAD), and extracorporeal membrane oxygenation; while inotropes, conventional LVAD, and heart transplantation are considered medium long-term treatment options [6]. Patients with Class C, D HF despite inotropic support and intra-aortic balloon pump placement are candidates for LVAD implantation either as a bridge to transplant (BTT) or as a destination therapy (DT). Heart transplantation is the therapy of choice for patients with stage D HF (i.e., refractory HF requiring advanced intervention) who do not have other significant comorbidities [8]. However, due to organ donor shortage, only a limited number of patients with end-stage HF are able to receive heart transplantation $[9,10]$. Extracorporeal ultrafiltration and peritoneal dialysis (PD) are also treatment considerations for HF patients with refractory volume overload despite intensified medical therapy. Several trials have explored the efficacy of ultrafiltration as a means of decongestion in subgroups of patients with acute HF who failed conventional diuretic-based approaches. Although the impact on long-term survival remains to be elucidated, ultrafiltration has shown promising results with regard to the reduction in the rate of hos- pital readmissions [11-14]. Several clinical trials have also shown beneficial intracorporeal ultrafiltration with PD in volume overloaded patients who have chronic refractory HF or cardiorenal syndrome (CRS). PD can be used as a long-term treatment option in advanced HF patients with concomitant kidney dysfunction who are otherwise not candidates for heart transplant, possibly in conjunction with advanced HF therapies $[15,16]$.

It is noteworthy that the estimation of kidney function in patients with advanced HF is challenging in that these patients are typically frail and sarcopenic due to their chronic illness and its comorbidities leading to reduction in creatinine production. As such, serum creatinine concentration (as well as creatinine-based formulae used to estimate kidney function) could be misleading in this patient population and overestimate their true level of kidney function. We need to be aware of this limitation when reviewing the results of studies on various aspects of kidneyheart interactions in severe HF. Furthermore, the concept of "worsening kidney function," commonly used in the cardiology literature especially in relation to acute HF, has been challenged in recent years by the fact that, in a growing number of settings, it neither reflects true kidney injury nor has an adverse impact on the outcomes. This concept has been extensively discussed elsewhere [17].

\section{Left Ventricular Assist Device}

LVAD is an intracorporeal mechanical pump that enhances cardiac output by unloading blood from the left ventricle to the ascending aorta. The pump draws blood 
from the left ventricle through inflow cannula implanted at the apex of left ventricle and pushes it into the ascending aorta through the outflow cannula. The first generation of LVAD used pulsatile flow pump design, which was approved for use as BTT in 1994 [18]. The number of patients receiving LVAD annually has increased exponentially from 98 in 2006 to 2,423 in 2014 [1]. LVAD has been used in patients with stage D HF with left ventricular dysfunction who are refractory to medical therapy as a BTT, as a bridge to recovery, or as a DT. It has shown to have a noteworthy impact on survival and quality of life [19]. A report from Interagency Registry for Mechanically Assisted Circulatory Support (INTERMACS) database showed that $46 \%$ of the patients received LVAD as a DT, $30 \%$ as a BTT, and $23 \%$ as a bridge to candidacy in anticipation to listing [20]. A randomized controlled trial, which included 129 patients who were ineligible for heart transplant showed a $48 \%$ reduction in the risk of death in those who received LVAD in comparison to medical therapy. It also showed improved functional capacity, quality of life, and end organ function in these patients waiting for transplant [18]. Hence, in the early 2000s, the interest in LVAD amplified exponentially among physicians providing care for patients with end-stage HF. However, despite the noteworthy benefits, the first generation of pulsatile flow LVADs had several complications including increased rate of infection, right HF, and kidney failure. The LVAD technology has greatly evolved over the last 2 decades with emergence of second and third generations of LVADs. The second and third generations of LVAD have a continuous flow, which is superior to the first-generation pulsatile flow. A randomized trial revealed improved survival ( 58 vs. $24 \%$ actuarial survival rate at 2 years, $p=$ 0.008 ) and less need for renal replacement therapy (RRT; incidence of kidney failure 16 vs. $24 \% p$ value $<0.001$ ) with the second generation of LVAD in comparison to the first generation [21]. The third generation of LVAD has a magnetically levitated centrifugal pump that employs a continuous flow technology and can be implanted intrapericardially utilizing bilateral or right-sided thoracotomy [22] (Fig. 1). The third generation of LVAD has shown to be non-inferior to the second generation of LVAD [23]. The supra-diaphragmatic approach to the implantation of third generation LVAD could potentially play a role on preserving the physical integrity of the peritoneal membrane and is helpful in patients who may require $\mathrm{PD}$ in future.

Heart Mate 3, approved by FDA in 2017, has a new feature of artificial pulse created by alteration in speed of pump every 2 seconds to reduce stasis of blood in the rotor (Fig. 1). Table 2 summarizes mechanical circulatory devices and their characteristics.

\section{Kidney Function Prior to LVAD Implantation}

$\mathrm{HF}$ and chronic kidney disease (CKD) are common coexisting ailments with common risk factors (e.g., hypertension and diabetes). Acute or chronic dysfunction of one often leads to acute or chronic dysfunction of the other, defined as CRS. ADHERE database reported moderate to severe kidney dysfunction (i.e., glomerular filtration rate $\leq 30 \mathrm{~mL} / \mathrm{min} / 1.73 \mathrm{~m}^{2}$ ) in $64 \%$ of 118,465 patients hospitalized with acute decompensated HF [24]. Chronic kidney dysfunction is also common in patients with chronic HF. A prospective study with 1,301 patients in outpatient HF clinic reported CKD to be present in about one fourth of the patients with chronic HF [25]. Chronic HF leads to increased neurohormonal activation, increased renal venous congestion and renin-angiotensinaldosterone system activation resulting in progressive decline in kidney function (i.e., CRS 2). On the other hand, one fourth of the patients admitted with acute HF develop acute kidney injury (AKI) secondary to decreased kidney perfusion from reduced cardiac output and/or high backward pressure and renal venous congestion (CRS type 1) [26]. Several observational studies have looked at kidney function prior to LVAD implantation and its impact on mortality. In a study on 3,363 patients who enrolled in INTERMACS, the mean baseline estimated GFR (eGFR) was $60 \pm 35 \mathrm{~mL} / \mathrm{min} / 1.73 \mathrm{~m}^{2}$, with a mean serum creatinine level of $1.4 \mathrm{mg} / \mathrm{dL}$ prior to implantation [27]. Preimplant kidney function is an important component of Heart Mate Risk Score; a well-validated prediction model that determines the risk of mortality in candidates eligible for LVAD. Of special note, every $1 \mathrm{mg} / \mathrm{dL}$ increase in serum creatinine concentration has been associated with doubling the risk of mortality [28]. A retrospective analysis of 4,917 patients from INTERMACS who had a continuous flow LVAD implantation revealed that patients with eGFR $<30 \mathrm{~mL} / \mathrm{min} / 1.73 \mathrm{~m}^{2}$ or those with dialysis dependence had an excessive mortality of $22 \%$ for the first 3 months. Even after initial 3 months, still significant but smaller differences in mortality were seen with increased degree of kidney dysfunction [29]. Due to poor outcomes in patients with advanced kidney function impairment (eGFR $<30 \mathrm{~mL} / \mathrm{min} / 1.73 \mathrm{~m}^{2}$ ), LVAD is generally considered a contraindication in this population unless a patient is being considered for combined heart- kidney trans- 


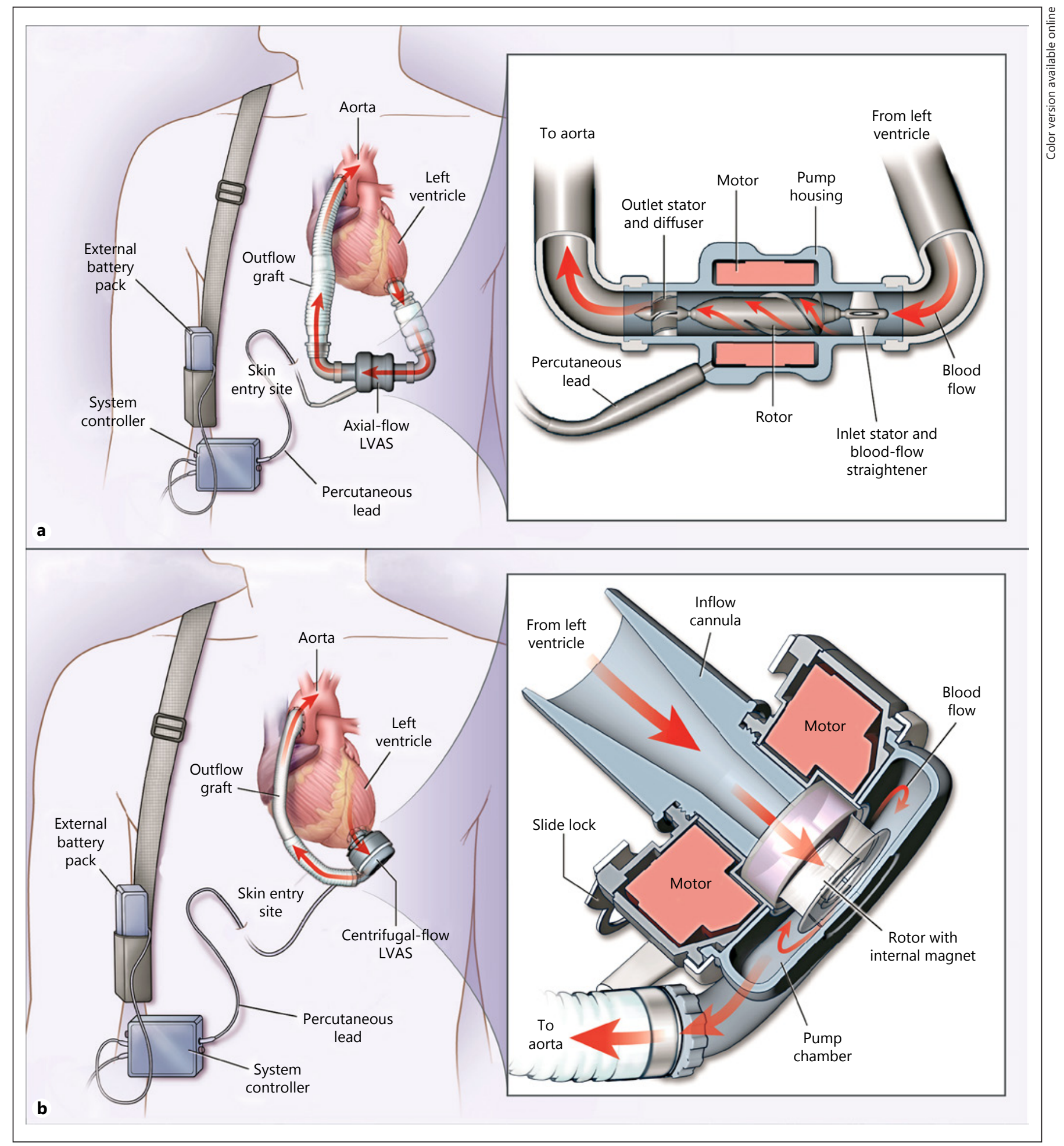

Fig. 1. a Illustrating the second generation of LVAD with axialflow pump design; the blood from the left ventricle enters into the pump where it flows along the axis of the rotor into the outflow cannula which drains into aorto. b Illustrating the third generation of LVAD with the fully magnetically levitated centrifugal-flow pump where the blood enters through the center of the rotor and flows outwards centrifugally into the outflow cannula. Produced with permission from [30]. LVAD, left ventricular assist device. 
Table 2. LVAD device characteristics and timeline for approval

\begin{tabular}{lllll}
\hline & Commercial name & Pump design & Implant site & FDA approval \\
\hline 1st generation & Heart Mate XVE & Pulsatile flow & Abdomen & $\begin{array}{l}\text { BTT 1995 } \\
\text { DT 2003 }\end{array}$ \\
\hline 2nd generation & Heart Mate II & Axial pump & Abdomen/chest & BTT 2008 \\
& & Continuous flow & DT 2010 \\
\hline 3rd generation & HeartWare HVAD & Centrifugal pump & Pericardium & BTT 2012 \\
& & Continuous flow & & DT 2017 \\
\hline & Heart Mate III & Centrifugal pump & Pericardium & BTT 2017 \\
& & Continuous flow 2018 \\
\end{tabular}

LVAD, left ventricular assist device; BTT, bridge to transplant; DT, destination therapy; FDA, Food and Drug administration.

plant. Moreover, LVAD implantation in patients who were dialysis-dependent seems unlikely to improve quality of life [31].

\section{Kidney Function after LVAD Implantation}

Kidney dysfunction is common after LVAD implantation. Analysis of $>12,000$ patients in INTERMACS database between 2008 and 2014 revealed that $12.3 \%$ of the patients developed AKI [20]. Similarly, kidney dysfunction was observed in $9.6 \%$ of patients $(n=332)$ after LVAD placement in a study by Slaughter et al. [32].

Kidney dysfunction in progressive $\mathrm{HF}$ is related to a reduced forward flow or elevated backward pressure. Since LVAD implantation improves cardiac output and tissue perfusion by increasing forward flow, an improvement in the kidney function after LVAD would be expected [11] (Fig. 2). However, the currently available data show an intriguing pattern of post-LVAD kidney function. In a study by Brisco et al. [27], nearly half of the patients (i.e., 48.9\%) initially experienced improvement in GFR after LVAD implantation. But this improvement was only short lived for majority of the patients; after 1 month, a decline in GFR was noted such that GFR was only $2.6 \mathrm{~mL} / \mathrm{min} / 1.73 \mathrm{~m}^{2}$ above the pre-LVAD level at 1 year. The patients without pre-implant kidney dysfunction had a decline in GFR at 1 year as opposed to patients with pre-implant kidney dysfunction who maintained GFR above the baseline despite the decline at the end of 1 month [27]. Another study compared kidney function in 165 patients implanted with LVAD who had pre-im- plant GFR $<40 \mathrm{~mL} / \mathrm{min} / 1.73 \mathrm{~m}^{2}$ (30 patients) in comparison to GFR of $>40 \mathrm{~mL} / \mathrm{min} / 1.73 \mathrm{~m}^{2}$ (135 patients). At 1 year, the patients with pre-implant GFR $<40 \mathrm{~mL} / \mathrm{min} / 1.73$ $\mathrm{m}^{2}$ were noted to have higher than baseline GFR in comparison to the patients with GFR $>40 \mathrm{~mL} / \mathrm{min} / 1.73 \mathrm{~m}^{2}$ whose kidney function returned to the pre-transplant baseline [33]. An observational study with 59 patients examined the long-term impact of LVAD on kidney function beyond 1 year. It showed that patients with pre-op GFR above $60 \mathrm{~mL} / \mathrm{min} / 1.73 \mathrm{~m}^{2}$ had a decrease in GFR after 1 month; at 2-3 year follow-up, GFR was significantly worse than baseline. However, in patients with preimplant GFR $<60 \mathrm{~mL} / \mathrm{min} / 1.73 \mathrm{~m}^{2}$, the kidney function initially improved but then declined to the baseline at the end of 3 years [34]. Overall, these studies suggest that the patients who experienced the most benefit in kidney function from LVAD were not able to sustain it.

Several studies have evaluated the effect of changes in kidney function on patient's outcomes. Interestingly, the study on INTERMACS database revealed that patients with $>88 \%$ improvement in eGFR at 1 month experienced an increased mortality similar to the patients with worsening kidney function [27].

However, patients with moderate improvement in kidney function (22-47\%) had the best outcomes and lowest mortality [27]. This is consistent with findings from retrospective and observational studies that evaluated the impact of changes in kidney function on outcomes of patients treated for acute decompensated HF. Patients who showed improvement in their kidney function following treatment paradoxically had poor outcomes in comparison to those who experienced an in- 


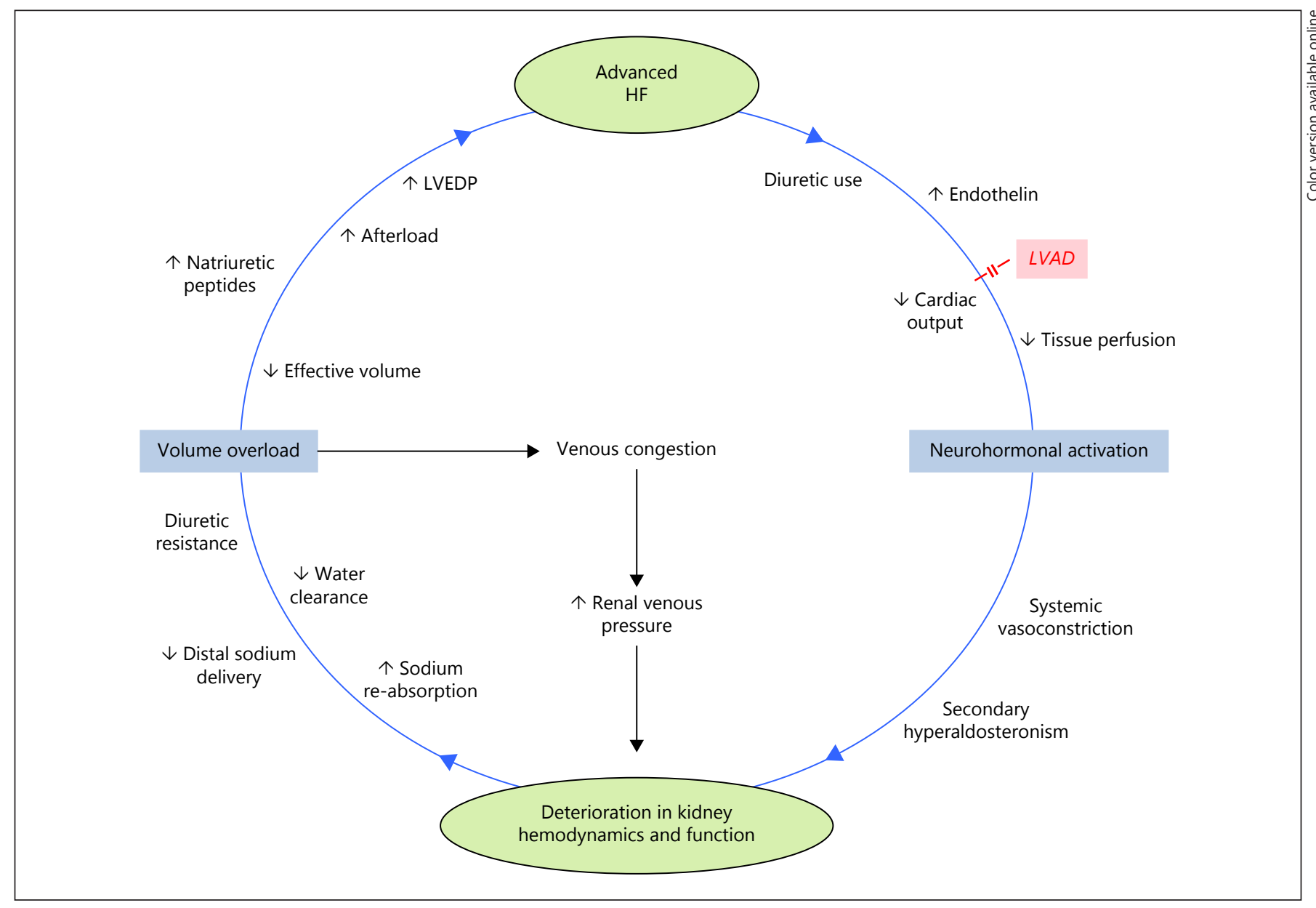

Fig. 2. Proposed pathophysiologic pathways underlying HF and kidney dysfunction. Advanced HF can lead to deterioration in kidney function via exacerbated neurohormonal activity (i.e., low forward flow) or through fluid overload and renal venous congestion (i.e., high backward pressure). Image adapted with publisher's per-

crease in serum creatinine [35]. These findings undermine the traditional notion that deterioration in kidney function, as defined by increase in serum creatinine, would translate into poor outcomes in the setting of HF. More recent data using various biomarkers have also challenged this notion [36].

Isolated heart transplantation is usually contraindicated in patients with underlying advanced CKD due to concern for progressive kidney disease from long term calcineurin inhibitor toxicity, poor outcomes in patients with CKD 3, 4, and 5 and risk of severe AKI in perioperative period [37]. A single-center observation study analyzed the effects of AKI in perioperative periods on 1 year mortality after heart transplantation in 346 patients. Mean pre-operative creatinine was $1.5 \mathrm{mg} / \mathrm{dL}$ and $61 \%$ of the patients had mission from [12]. LVAD could potentially break this vicious cycle via correction of low cardiac output. LVAD, left ventricular assist device, LVEDP, left ventricular end-diastolic pressure; HF, heart failure.

baseline eGFR of $<60 \mathrm{~mL} / \mathrm{min} / 1.73 \mathrm{~m}^{2}$. Severe AKI was associated with increased 1-year mortality [38].

Several hypotheses have been proposed to explain the perceived phenomenon of worsening kidney function at 1 month after LVAD implantation. One of the mechanisms has been related to development of right ventricular (RV) dysfunction after LVAD implantation, which develops in approximately $20-50 \%$ of the patients [39]. This has been attributed to increased RV preload to compensate for improved cardiac output post LVAD, and left-sided shift in intraventricular septum, which decreases RV contractility [40]. Also, previous studies have shown that an increase in RV filling pressures out of proportion to the left ventricular filling pressure can cause kidney dysfunction and increase mortality. A retrospec- 
tive study on 367 patients with acute decompensated HF and increased intra cardiac pressure showed that increasing the ratio of right atrial pressure to pulmonary capillary wedge pressure is inversely related to baseline GFR [41]. Similarly, a prospective study with 484 patients with LVAD found that a high pre-LVAD central venous pressure to pulmonary capillary wedge pressure ratio was an independent predictor for post-LVAD RV failure [42].

Another plausible mechanism for post-LVAD increase in serum creatinine is attributed to the structural changes in arterial system secondary due to lack of pulsatility. A study on aortic wall tissue samples from patients with LVAD showed an increase in aortic wall stiffness related to increase in total wall thickness, increase in collagen, and decrease in elastin when compared to non-failing heart donors [43]. Data from experimental animal studies support this hypothesis. A study comparing histological changes in renal arteries of calves with LVAD, $\mathrm{RV}$ assist device, and total artificial pulsatile heart with normal controls showed changes in the renal artery of the animals similar to those seen in the aorta. It also showed development of severe peri-arteritis and upregulation of local renin-angiotensin-aldosterone in the inflammatory cells in continuous flow LVAD group [44]. Despite the histological and morphological changes seen in vascular and renal tissues in animal and human studies, clinically no difference has been noted in kidney function with continuous or pulsatile flow. Subgroup analysis of kidney function in patients with continuous flow or pulsatile flow LVAD showed similar trend of change in GFR at 1 month, 6 month and at 1 year in a study on 3,363 patients [27]. Another retrospective study that assessed kidney function in 92 patients with LVAD implantation showed significant improvement in GFR at week 1, 4, and 12 weeks post implantation, which was similar between patients who received continuous flow LVAD compared to pulsatile flow device [45].

Pigment-induced tubular injury from hemolysis related to LVAD implantation could be the reason for the development of AKI in a subset of patients. High pump speed (3,000 rpm in centrifugal flow device) and thrombosis causing alteration in blood flow can lead to hemolysis from shear stress on the red blood cells, release hemoglobin and iron into circulation, and damage the kidney through inflammation or precipitation $[46,47]$.

Another possible explanation for perceived development of kidney dysfunction after LVAD could be related to the fact that their baseline GFR could be overestimated due to underappreciated reduction in creatinine production [48]. It is noteworthy that the kidney function in these studies has generally been assessed through creatininebased formulae which are affected by decreased creatinine production due to known frailty and sarcopenia of this patient population [49-51]. Improvement in overall health, enhanced appetite, and increase in muscle mass after LVAD implantation could potentially explain some degree of decrease in GFR in these patients. For precise evaluation of the impact of LVAD on kidney function, future studies are needed to longitudinally assess patient's nutritional status and muscle mass in correlation with observed changes in serum creatinine concentrations and more recent renal biomarkers. Moreover, a novel generation of LVAD (i.e., HeartMate 3 ) that was recently approved by the FDA offers the technical feature of "artificial pulse," hence considered more physiologically similar to the heart. Thelongterm effects of this new generation of LVAD on the kidney function remains unidentified at this time [52].

\section{LVAD and RRT}

As previously mentioned, patients with severe kidney dysfunction are in general not considered for LVAD implantation due to poor outcomes. However, RRT is needed in a subset of patients who develop post-LVAD AKI. In a study by Topkara et al. [53] on 389 patients, 44 (11.3\%) experienced AKI that needed RRT; most of these patients (73\%) remained on maintenance dialysis thereafter. Since PD is rarely used for management of patients with AKI, almost all patients with post-LVAD AKI who need RRT will receive hemodialysis. However, PD can be considered an option for chronic RRT with a number of potential advantages over hemodialysis in these patients such as the ability to provide continuous gentle ultrafiltration with minimum impact on hemodynamic status. As previously mentioned, PD has shown very promising results with regard to its decongestive properties in those patients with advanced HF and fluid overload who are refractory to diuretic-based therapeutic strategies [15, 16]. Moreover, in contrast to hemodialysis, PD does not require repetitive access to a vascular bed, hence resulting in less likelihood of bloodstream infection, which is a major risk in patients with LVAD. While there are anecdotal reports on the use of PD in patients with LVAD [54, 55], more data are needed to precisely evaluate its impact on overall outcomes in this patient population.

Hemodialysis catheter continues to be the most common dialysis access in these patients despite its established association with an increased risk of infection and morbidity. Although establishment of arteriovenous fis- 
tula (AVF) is promoted in patient with end-stage kidney disease, the creation of autogenous access has been argued against in patients with LVAD based on several theoretical considerations. It has been hypothesized that maturation of AVF would need pulsatile flow that is absent in these patients. Moreover, patients with chronic HF might have poor vasculature due to frequent use of peripherally inserted venous catheters, limiting their options for creation of an AVF. It is also postulated that these patients often require RRT temporarily; recovery of kidney function is expected post transplantation. Finally, some authors have expressed concern regarding high out HF related to autogenous access [56].

Nevertheless, several case reports of successful creation of AVF in patients with LVAD have been published; some patients might require balloon-assisted maturation $[57,58]$. In summary, while there is no strong evidence against the creation of autogenous access in patients with LVAD, theoretical concerns do exist regarding maturation, functionality, and consequences of these accesses. Due to the unacceptably high incidence of catheter-related infection and morbidity in patients with stable clinical condition in whom long-term RRT is anticipated, it is reasonable to consider creation of an AVF.

The optimal renal replacement for patients with LVAD remains a clinical dilemma. Although hemodialysis remains the most commonly used modality in patients with LVAD it poses several challenges such as the difficulty in creating AVF as described above, risk of blood stream infections, lack of trained staff in outpatient hemodialysis unit with appropriate expertise in measuring blood pressure and understanding LVAD parameters to gauge signs of hemodynamic instability (i.e., low pulsatility index may be suggestive of excessive UF) [59]. PD appears to be a more acceptable alternative especially with the advent of newer models of LVAD which do not affect the peritoneal integrity, promise of gentle UF, and decreased risk of blood stream associated infections. However, we must recognize that there are no randomized controlled trials to support this notion; nonetheless, with increasing familiarity of nephrologists and cardiologists with LVAD, the clinical paradigm toward increased use of PD may emerge in this subset of patients.

\section{Conclusion}

Kidney dysfunction is common among patients with advanced HF who are referred for LVAD therapy. Since presence of pre-implant kidney dysfunction has been associated with adverse outcomes after LVAD implantation, this therapy has conventionally been avoided in those patients with severe kidney impairment. While AKI is a relatively common complication after LVAD implantation, the majority of the patients are noted to have an improvement in eGFR due to the salutary impact of LVAD on end-organ perfusion and renal hemodynamics. However, this benefit is typically short lived and is followed by a gradual degradation in kidney function that can indeed be confounded by improvement in general state of health, nutrition, and muscle mass. Hemodialysis, the most commonly used RRT modality in patients with post LVAD AKI, is often challenging due to lack of expertise in assessing reliable blood pressure by the dialysis staff, difficulty in determination of the degree of fluid overload, and the risk of intradialytic hypotension.

With increasing use of LVAD and significant contribution of kidney function to the patients' overall outcomes, a multidisciplinary team management approach is required for optimal management of these patients especially those who require long-term RRT. Future research is needed to more precisely assess longitudinal changes in kidney function using various biomarkers of kidney injury. Moreover, more data are needed on choices of dialysis access and modality before a specific approach can be advocated.

\section{Disclosure Statement}

No specific financial support was obtained for preparation of this article. M.K. has no potential conflict of interest to declare with respect to this paper. A.K. is a consultant for CHF Solutions, Inc.

\section{Author Contributions}

M.K. was responsible for drafting article and data collection. A.K. was responsible for drafting manuscript and revising the article critically for important intellectual content.

\section{References}

1 Benjamin EJ, Virani SS, Callaway CW, Chamberlain AM, Chang AR, Cheng S, et al.; American Heart Association Council on Epidemiology and Prevention Statistics Committee and Stroke Statistics Subcommittee. Heart Disease and Stroke Statistics-2018 Update: A Report From the American Heart Association. Circulation. 2018 Mar;137(12):e67-492.

2 Barker WH, Mullooly JP, Getchell W. Changing incidence and survival for heart failure in a well-defined older population, 1970-1974 and 1990-1994. Circulation. 2006 Feb;113(6): 799-805. 
3 Nkomo VT, Gardin JM, Skelton TN, Gottdiener JS, Scott CG, Enriquez-Sarano M. Burden of valvular heart diseases: a population-based study. Lancet. 2006 Sep;368(9540):1005-11.

4 Roger VL. Epidemiology of heart failure. Circ Res. 2013 Aug;113(6):646-59.

5 Heidenreich PA, Albert NM, Allen LA, Bluemke DA, Butler J, Fonarow GC, et al.; American Heart Association Advocacy Coordinating Committee; Council on Arteriosclerosis, Thrombosis and Vascular Biology; Council on Cardiovascular Radiology and Intervention; Council on Clinical Cardiology; Council on Epidemiology and Prevention; Stroke Council. Forecasting the impact of heart failure in the United States: a policy statement from the American Heart Association. Circ Heart Fail. 2013 May;6(3):60619.

6 Yancy CW, Jessup M, Bozkurt B, Butler J, Casey DE Jr, Drazner MH, et al.; American College of Cardiology Foundation; American Heart Association Task Force on Practice Guidelines. 2013 ACCF/AHA guideline for the management of heart failure: a report of the American College of Cardiology Foundation/American Heart Association Task Force on Practice Guidelines. J Am Coll Cardiol. 2013 Oct;62(16):e147-239.

7 The Criteria Committee of the New York Heart Association. Nomenclature and Criteria for Diagnosis of Diseases of the Heart and Great Vessels. 9th ed. Boston (Mass): Little, Brown \& Co; 1994. pp. 253-6.

8 McMurray JJ, Adamopoulos S, Anker SD, Auricchio A, Böhm M, Dickstein K, et al.; ESC Committee for Practice Guidelines. ESC Guidelines for the diagnosis and treatment of acute and chronic heart failure 2012: The Task Force for the Diagnosis and Treatment of Acute and Chronic Heart Failure 2012 of the European Society of Cardiology. Developed in collaboration with the Heart Failure Association (HFA) of the ESC. Eur Heart J. 2012 Jul;33(14):1787-847.

9 Lund LH, Khush KK, Cherikh WS, Goldfarb S, Kucheryavaya AY, Levvey BJ, et al.; International Society for Heart and Lung Transplantation. The Registry of the International Society for Heart and Lung Transplantation: Thirty-fourth Adult Heart Transplantation Report-2017; Focus Theme: Allograft ischemic time. J Heart Lung Transplant. 2017 Oct; 36(10):1037-46.

10 Miller LW, Guglin M. Patient selection for ventricular assist devices: a moving target. J Am Coll Cardiol. 2013 Mar;61(12):1209-21.

11 Kazory A. Ultrafiltration Therapy for Heart Failure: Balancing Likely Benefits against Possible Risks. Clin J Am Soc Nephrol. 2016 Aug;11(8):1463-71.

12 Kazory A. Cardiorenal syndrome: ultrafiltration therapy for heart failure-trials and tribulations. Clin J Am Soc Nephrol. 2013 Oct; 8(10):1816-28

13 Pourafshar N, Karimi A, Kazory A. Extracorporeal ultrafiltration therapy for acute de- compensated heart failure. Expert Rev Cardiovasc Ther. 2016;14(1):5-13.

14 Ross EA, Kazory A. Ultrafiltration therapy for cardiorenal syndrome: physiologic basis and contemporary options. Blood Purif. 2012; 34(2):149-57.

15 Kazory A. Peritoneal dialysis for chronic cardiorenal syndrome: lessons learned from ultrafiltration trials. World J Cardiol. 2015 Jul; 7(7):392-6.

16 Courivaud C, Kazory A. Can we treat fluid overload with fluid? Role of peritoneal dialysis in management of heart failure. Eur J Heart Fail. 2012 May; 14(5):461-3.

17 Kazory A, Ronco C. Are We Barking Up the Wrong Tree? Rise in Serum Creatinine and Heart Failure. Blood Purif. 2019 Jun 19:1-3

18 Rose EA, Gelijns AC, Moskowitz AJ, Heitjan DF, Stevenson LW, Dembitsky W, et al.; Randomized Evaluation of Mechanical Assistance for the Treatment of Congestive Heart Failure (REMATCH) Study Group. Longterm use of a left ventricular assist device for end-stage heart failure. N Engl J Med. 2001 Nov;345(20):1435-43.

19 Kirklin JK, Pagani FD, Kormos RL, Stevenson LW, Blume ED, Myers SL, et al. Eighth annual INTERMACS report: special focus on framing the impact of adverse events. J Heart Lung Transplant. 2017 Oct;36(10):1080-6.

20 Kirklin JK, Naftel DC, Pagani FD, Kormos RL, Stevenson LW, Blume ED, et al. Seventh INTERMACS annual report: 15,000 patients and counting. J Heart Lung Transplant. 2015 Dec;34(12):1495-504.

21 Slaughter MS, Rogers JG, Milano CA, Russell SD, Conte JV, Feldman D, et al.; HeartMate II Investigators. Advanced heart failure treated with continuous-flow left ventricular assist device. N Engl J Med. 2009 Dec;361(23): 2241-51.

22 Schmitto JD, Molitoris U, Haverich A, Strueber M. Implantation of a centrifugal pump as a left ventricular assist device through a novel, minimized approach: upper hemisternotomy combined with anterolateral thoracotomy. J Thorac Cardiovasc Surg. 2012 Feb;143(2): 511-3.

23 Aaronson KD, Slaughter MS, Miller LW, McGee EC, Cotts WG, Acker MA, et al.; HeartWare Ventricular Assist Device (HVAD) Bridge to Transplant ADVANCE Trial Investigators. Use of an intrapericardial, continuous-flow, centrifugal pump in patients awaiting heart transplantation. Circulation. 2012 Jun;125(25):3191-200.

24 Heywood JT, Fonarow GC, Costanzo MR, Mathur VS, Wigneswaran JR, Wynne J; ADHERE Scientific Advisory Committee and Investigators. High prevalence of renal dysfunction and its impact on outcome in 118,465 patients hospitalized with acute decompensated heart failure: a report from the $\mathrm{AD}$ HERE database. J Card Fail. 2007 Aug;13(6): 422-30.

25 Hebert K, Dias A, Delgado MC, Franco E, Tamariz L, Steen D, et al. Epidemiology and survival of the five stages of chronic kidney disease in a systolic heart failure population. Eur J Heart Fail. 2010 Aug;12(8): 861-5.

26 Dar O, Cowie MR. Acute heart failure in the intensive care unit: epidemiology. Crit Care Med. 2008 Jan;36(1 Suppl):S3-8.

27 Brisco MA, Kimmel SE, Coca SG, Putt ME Jessup M, Tang WW, et al. Prevalence and prognostic importance of changes in renal function after mechanical circulatory support. Circ Heart Fail. 2014 Jan;7(1):68-75.

28 Cowger J, Sundareswaran K, Rogers JG, Park SJ, Pagani FD, Bhat G, et al. Predicting survival in patients receiving continuous flow left ventricular assist devices: the HeartMate II risk score. J Am Coll Cardiol. 2013 Jan;61(3): $313-21$.

29 Kirklin JK, Naftel DC, Kormos RL, Pagani FD, Myers SL, Stevenson LW, et al. Quantifying the effect of cardiorenal syndrome on mortality after left ventricular assist device implant. J Heart Lung Transplant. 2013 Dec; 32(12):1205-13.

30 Mehra MR, Naka Y, Uriel N, Goldstein DJ, Cleveland JC Jr, Colombo PC, et al.; MOMENTUM 3 Investigators. A Fully Magnetically Levitated Circulatory Pump for Advanced Heart Failure. N Engl J Med. 2017 Feb; 376(5):440-50.

31 Cook JL, Colvin M, Francis GS, Grady KL, Hoffman TM, Jessup M, et al.; American Heart Association Heart Failure and Transplantation Committee of the Council on Clinical Cardiology; Council on Cardiopulmonary, Critical Care, Perioperative and Resuscitation; Council on Cardiovascular Disease in the Young; Council on Cardiovascular and Stroke Nursing; Council on Cardiovascular Radiology and Intervention; and Council on Cardiovascular Surgery and Anesthesia. Recommendations for the Use of Mechanical Circulatory Support: Ambulatory and Community Patient Care: A Scientific Statement From the American Heart Association. Circulation. 2017 Jun; 135(25): e1145-58.

32 Slaughter MS, Pagani FD, McGee EC, Birks EJ, Cotts WG, Gregoric I, et al.; HeartWare Bridge to Transplant ADVANCE Trial Investigators. HeartWare ventricular assist system for bridge to transplant: combined results of the bridge to transplant and continued access protocol trial. J Heart Lung Transplant. 2013 Jul;32(7):675-83

33 Raichlin E, Baibhav B, Lowes BD, Zolty R, Lyden ER, Vongooru HR, et al. Outcomes in Patients with Severe Preexisting Renal Dysfunction After Continuous-Flow Left Ventricular Assist Device Implantation. ASAIO J. 2016 May-Jun;62(3):261-7.

34 Yoshioka D, Takayama H, Colombo PC, Yuzefpolskaya M, Garan AR, Topkara VK, et al. Changes in End-Organ Function in $\mathrm{Pa}$ tients With Prolonged Continuous-Flow Left Ventricular Assist Device Support. Ann Thorac Surg. 2017 Mar;103(3):717-24. 
35 Kazory A, Elkayam U. Cardiorenal interactions in acute decompensated heart failure: contemporary concepts facing emerging controversies. J Card Fail. 2014 Dec;20(12):1004-11.

36 Ahmad T, Jackson K, Rao VS, Tang WH, Brisco-Bacik MA, Chen HH, et al. Worsening Renal Function in Patients With Acute Heart Failure Undergoing Aggressive Diuresis Is Not Associated With Tubular Injury. Circulation. 2018 May;137(19):2016-28.

37 DePasquale EC, Cheng RK, Ardehali A, Baas A, Cadeiras M, Cruz D, et al. Influence of Pre-Transplant Chronic Kidney Disease (CKD) on Adult Heart Transplant (HT) Outcomes. J Heart Lung Transplant. 2013 Apr; 32(4):S166

38 Schiferer A, Zuckermann A, Dunkler D, Eskandary F, Bernardi M, Hiesmayr M, et al. Acute Kidney Injury and Outcome After Heart Transplantation: Large Differences in Performance of Scoring Systems. Transplantation. 2016 Nov; 100(11):2439-46.

39 Meineri M, Van Rensburg AE, Vegas A. Right ventricular failure after LVAD implantation: prevention and treatment. Best Pract Res Clin Anaesthesiol. 2012 Jun;26(2):217-29.

40 Argiriou M, Kolokotron SM, Sakellaridis T, Argiriou O, Charitos C, Zarogoulidis P, et al. Right heart failure post left ventricular assist device implantation. J Thorac Dis. 2014 Mar 6 Suppl 1:S52-9.

41 Grodin JL, Drazner MH, Dupont M, Mullens W, Taylor DO, Starling RC, et al. A disproportionate elevation in right ventricular filling pressure, in relation to left ventricular filling pressure, is associated with renal impairment and increased mortality in advanced decompensated heart failure. Am Heart J. 2015 Jun;169(6):806-12.

42 Kormos RL, Teuteberg JJ, Pagani FD, Russell SD, John R, Miller LW, et al.; HeartMate II Clinical Investigators. Right ventricular failure in patients with the HeartMate II continuous-flow left ventricular assist device: incidence, risk factors, and effect on outcomes. J Thorac Cardiovasc Surg. 2010 May; 139(5): 1316-24.
43 Ambardekar AV, Hunter KS, Babu AN, Tuder RM, Dodson RB, Lindenfeld J. Changes in Aortic Wall Structure, Composition, and Stiffness With Continuous-Flow Left Ventricular Assist Devices: A Pilot Study. Circ Heart Fail. 2015 Sep;8(5):944-52.

44 Ootaki C, Yamashita M, Ootaki Y, Kamohara K, Weber S, Klatte RS, et al. Reduced pulsatility induces periarteritis in kidney: role of the local renin-angiotensin system. J Thorac Cardiovasc Surg. 2008 Jul;136(1):150-8.

45 Sandner SE, Zimpfer D, Zrunek P, Dunkler D, Schima H, Rajek A, et al. Renal function after implantation of continuous versus pulsatile flow left ventricular assist devices. J Heart Lung Transplant. 2008 May;27(5):469-73

46 Schechter MA, Daneshmand MA, Patel CB, Blue LJ, Rogers JG, Milano CA. Outcomes after implantable left ventricular assist device replacement procedures. ASAIO J. 2014 JanFeb;60(1):44-8.

47 Mehra MR, Uriel N, Naka Y, Cleveland JC Jr, Yuzefpolskaya M, Salerno CT, et al.; MOMENTUM 3 Investigators. A Fully Magnetically Levitated Left Ventricular Assist Device - Final Report. N Engl J Med. 2019 Apr; 380(17):1618-27.

48 Brisco MA, Hale A, Zile MR, Heyward DP, Cook JL, Uber W, et al. Patients Undergoing LVAD Placement Demonstrate Marked Sarcopenia Leading to Overestimation of PreImplant Glomerular Filtration Rate. J Heart Lung Transplant. 2015 Apr;34(4):S165.

49 Bottiger BA, Nicoara A, Snyder LD, Wischmeyer PE, Schroder JN, Patel CB, et al. Frailty in the End-Stage Lung Disease or Heart Failure Patient: Implications for the Perioperative Transplant Clinician. J Cardiothorac Vasc Anesth. 2019 May;33(5):1382-92.

50 Heberton GA, Nassif M, Bierhals A, Novak E, LaRue SJ, Lima B, et al. Usefulness of Psoas Muscle Area Determined by Computed Tomography to Predict Mortality or Prolonged Length of Hospital Stay in Patients Undergoing Left Ventricular Assist Device Implantation. Am J Cardiol. 2016 Nov; 118(9):1363-7.
51 Beddhu S, Samore MH, Roberts MS, Stoddard GJ, Pappas LM, Cheung AK. Creatinine production, nutrition, and glomerular filtration rate estimation. J Am Soc Nephrol. 2003 Apr; 14(4):1000-5.

52 Mehra MR, Goldstein DJ, Uriel N, Cleveland JC Jr, Yuzefpolskaya M, Salerno C, et al.; MOMENTUM 3 Investigators. Two-Year Outcomes with a Magnetically Levitated Cardiac Pump in Heart Failure. N Engl J Med. 2018 Apr;378(15):1386-95.

53 Topkara VK, Coromilas EJ, Garan AR, Li RC, Castagna F, Jennings DL, et al. Preoperative Proteinuria and Reduced Glomerular Filtration Rate Predicts Renal Replacement Therapy in Patients Supported With ContinuousFlow Left Ventricular Assist Devices. Circ Heart Fail. 2016 Dec;9(12):e002897.

54 Guglielmi AA, Guglielmi KE, Bhat G, Siemeck R, Tatooles AJ. Peritoneal dialysis after left ventricular assist device placement. ASAIO J. 2014 Jan-Feb;60(1):127-8.

55 Thomas BA, Logar CM, Anderson AE. Renal replacement therapy in congestive heart failure requiring left ventricular assist device augmentation. Perit Dial Int. 2012 Jul-Aug; 32(4):386-92.

56 Roehm B, Vest AR, Weiner DE. Left Ventricular Assist Devices, Kidney Disease, and Dialysis. Am J Kidney Dis. 2018 Feb;71(2):25766.

57 Chin AI, Tong K, McVicar JP. Successful Hemodialysis Arteriovenous Fistula Creation in a Patient With Continuous-Flow Left Ventricular Assist Device Support. Am J Kidney Dis. 2017 Feb;69(2):314-6.

58 Sasson T, Wing RE, Foster TH, Kashyap R, Butani D, Waldman DL. Assisted maturation of native fistula in two patients with a continuous flow left ventricular assist device. J Vasc Interv Radiol. 2014 May;25(5): 781-3.

59 Sen A, Larson JS, Kashani KB, Libricz SL, Patel BM, Guru PK, et al. Mechanical circulatory assist devices: a primer for critical care and emergency physicians. Crit Care. 2016 Jun;20(1):153. 